\title{
White Elephants and Donor-Funded Clinical Research in Developing Countries
}

\section{Catherine N Kibirige*}

MSI- Pharma Contract Scientist, London, England, United Kingdom

I had the amazing privilege of volunteering and then working for the clinical epidemiology project in Africa where HIV/AIDS was first characterized when I finished my undergraduate studies. I saw it transition from a very basic field station in a very rustic and desolate rural setting to a "State-of-the-Art" facility. It was great to be involved in the capacity-building of the country's healthcare system.

As an African who had grown up in a very middle-class multicultural urban setting and migrated to the United Kingdom before moving to rural Africa there were some things, though, that stood out like a very sore thumb. I remember my excitement when I was offered a job with the project and was told that I would help an American collaborator set up a new laboratory for his particular funding agency and introduce in-country HIV viral-load testing. It was his first time in Africa and it was interesting to witness his cultural acclimatization and observe how the locals interacted with him and with me. When a laboratory was built and equipment and reagents started arriving it was hard not to notice some of the extravagances. Absolutely everything was imported from America, from the bleach, to the paper towels, to the cotton swabs. There were guidelines and restrictions as to the salaries they could provide to locals and they had restrictions governing the infrastructure they could and could not build. My boss was not able to improve housing conditions for the staff or increase salaries beyond a certain point so the opulence in the laboratory was a very stark contrast to the living conditions for most of the project employees. As most of the skilled personnel were not from this particular rural area, they came in from the city during the week and rented shanty rooms in the small town. They cooked outside on charcoal stoves and shared bathrooms and latrines with their neighbors. It was very squalid living. This really stood out to me because when I did the conversion from dollars to local currency for one of these boxes of imported paper-towels, I realized that the cost was very easily the cleaner's weekly salary. As I had never worked with an international agency before, it was difficult to understand. I raised the point that paper and cotton goods as well as bleach and other supplies were available locally. We grow plenty of cotton in East Africa and have plenty of paper mills. Couldn't we source some locally made laboratory coats at the very least? The reply was always that the quality was not the same, the supply chain was unreliable and they needed to maintain the same standards as in the U.S.; if the research findings were to be publishable and comparable with other studies.

There were also some disparaging attitudes concerning the ability of the locals to perform complex tasks. I remember suggesting, for example, that they train the staff to calibrate the pipettes and maintain some of the equipment as it was costing the project a considerable sum of money to have foreigners come in to calibrate and validate equipment every-so-often. My boss just shook his head and whispered that the staff would not be able to manage that properly. These physicians and laboratory professionals were running field clinics and performing surgery, applying and getting accepted into some of the best Universities in the world and graduating with advanced degrees.

I too eventually got sponsorship to study at a leading U.S. university and was full of enthusiasm and ideas for the project but was surprised to find a rather cold response when I tried to return home. To begin with, the project now had many locally trained personnel who could perform the tasks they needed and they did not really have a place for a basic scientist, or so they said. In reality, people wanted to know if I was bringing funding and were not really interested in any ideas I had beyond that. I visited the field station where I had worked, 8 to 9 years ago by this time, and it was great to see how far things had come but also sad to see how much they had remained the same. I was writing a proposal and doing some research developing ultra-sensitive viral assays for HIV and thought it would be brilliant if the local scientists could be taught how to develop and validate their own diagnostic tests. Everyone shook their heads, including physicians who had quite extensive microbiology training.

I told them, "Look, you have all the equipment here, all the sequence data is available online, it would save you a lot of money if you could develop and validate in-house diagnostics instead of relying on expensive imported kits and donor funding".

The project had down-sized considerably over the years as various studies came to an end. There were three "state-of-the-art" thermocyclers sitting idle on the shelf. My guide boasted that they were now doing sequencing and all kinds of advanced work, including Ebola vaccine development in Uganda.

I eventually returned to the United States and felt validated, somewhat, when I was approached by a pharmaceutical company about helping them develop assays for their new advanced technology. They, however, were not at all interested in funding or commercializing the lower-cost versions for developing countries try-as-I-might to persuade them. The project with them ended successfully. I am still trying to find collaborators to test out the lower-cost in-house assays and test ideas for their implementation, on the other-hand.

I found great solace when I attended a number of conferences run by the Christian Connections for International Health in the United States. Most of the groups involved with the organization are small faith-based agencies operating on a shoe-string budget and they are all for efficiency and empowering local people and building true sustainability. I attended a talk by an organization that collects second hand equipment from laboratories in the United States and trains volunteers in how to revive and maintain them, for example. The speaker literally took most of the words out of my mouth. I remember

*Corresponding author: Catherine N Kibirige, MSI- Pharma Contract Scientist London, England, United Kingdom, E-mail: kibirigec@gmail.com

Received April 16, 2016; Accepted April 19, 2016; Published April 25, 2016

Citation: Kibirige CN (2016) White Elephants and Donor-Funded Clinical Research in Developing Countries. J AIDS Clin Res 7: 566. doi:10.4172/2155-6113.1000566

Copyright: (c) 2016 Kibirige CN. This is an open-access article distributed under the terms of the Creative Commons Attribution License, which permits unrestricted use, distribution, and reproduction in any medium, provided the original author and source are credited. 
him mentioning how his organization, sends volunteers out on mission trips to introduce the equipment to various projects and train the locals in their maintenance. They help to provide a supply chain for spare parts including brokering deals with companies for equipment that has been discontinued. The organization also visits local clinics and hospitals and helps revitalize equipment that is sitting dormant in their facilities. The speaker talked about sometimes finding entire hospital wards full of defunct equipment and talked about the excitement of being able to bring the equipment back into effective use.

I believe that when large agencies fund clinical research in developing countries and work towards building local capacity, they really need to think more about how things will be sustained once the studies end. Will the clinic or hospital where the research has been conducted be able to continue running diagnostic tests, support staff salaries and provide effective services to the community? Will the scientists in the University have the ability to develop their own research ideas, write proposals, get them funded and continue to use the stateof-the art equipment provided to them? What things can the project do to facilitate this? An international study might call for a particularly advanced diagnostic test in order to obtain particular data and compare findings across various sites, for example, but in the process of doing the research, perhaps the study could compare and validate a more locally available diagnostic against their gold-standard. It may not be as sensitive but could be clinically useful and more sustainable for the hospital to continue using once the study has ended. They could help to improve the local infrastructure or the supply-chain required to maintain various services.
One trend that has taken off in more sociological research is providing small loans or income-generating projects to study participants so that they are empowered for the future in the process of participating in research. We desperately need something similar for medical research. We need to think more about how hospitals, clinics and universities can develop income-generating projects that allow them to become more self sufficient and less donor-dependent. Why not attach a "state-of-the-art" paper mill or garment factory to the hospital so that staff can continue to have the basic paper and cotton goods required for the clinic in the future. They would help supply the local community and generate an income. Why not teach the clinic how to make more of its own reagents using locally available raw materials and validate them against international reagents. It could be something as simple as manufacturing Oral Rehydration Salts in a "state-of-the-art" or even basic income-generating facility.

We import designer clothes, cars and furniture into African countries with no problem. The rich and middle-class are living very extravagant lives in very stark contrast to the poor. It does not make sense that hospitals and clinics are lying in dereliction in the midst of all this opulence. We should not rely on world-bank funding to get a hospital back into service or on a foreign study to revitalize a particular ward. Again, I say, why not develop our own in-house "home-brew" diagnostics and validate them against international gold standards, so that when a project or study pulls out, we are not turning patients away because we have "run out of kits"? Why not insist that local and foreign research collaborators make provision for sustainability when they do research in developing countries? It is time to think, and act outside the box. 